with mental health problems, and better for society as a whole. Only a small proportion of people with mental health problems will ever need to be detained, usually because they want to harm themselves, and on some occasions because they are at risk of harming others. These people should have the same rights and protections as anyone else to whom capacity legislation applies,' he said.

\section{Mental health day in the Middle East}

On 10 October 2009, Iraq celebrated a Mental Health Day in Baghdad. The celebration was hosted by the Al-Rashad Mental Hospital with the support of the Al-Mada Media Agency. It was attended by the Minister for the Environment, the National Advisor for Mental Health, the Health Director General for Baghdad, the President of the Iraqi Psychiatric Association, the Chairman of Middle Eastern Division of the Royal College of Psychiatrists, and a large number of nongovernmental organisations, mental health professionals, patients, families and the media. Dr Jameel Muslim, Hospital Director, welcomed the guests, gave a historical account of the hospital, and with his colleagues highlighted activities and developments, particularly in the areas of rehabilitation and continuing professional development in the hospital and throughout Iraq.

Dr Sabah Sadik, Chairman of the Middle Eastern Division, congratulated all on the progress and reiterated the Royal College of Psychiatrists' commitment to mental health services in the Middle East. Patients in the hospital contributed to the event through musical and recreational activities.

The celebration ended with an art exhibition by patients followed by lunch by the lake at the hospital. The event was well publicised by the media, enjoyed by all and had a positive impact on the public.

\section{Regional meeting of the Middle Eastern Division}

The regional meeting of the Royal College of Psychiatrists' Middle Eastern Division took place in Baghdad from 12 to 14 October 2009, in collaboration with the Ministry of Health, the International Medical Corps and the Iraqi Psychiatric Association. His Excellency the Minister of Health opened the meeting; in attendance were heads of organisations, officials, psychiatrists and other mental health professionals. The scientific programme included keynote speeches, panel discussions, lectures and workshops. The conference covered a variety of topics, including integrating mental health into primary care, trauma, undergraduate and postgraduate education, clinical quality and substance misuse. Around 700 delegates attended the meeting, from the UK, Europe, the USA, Egypt, Jordan, Syria, Bahrain, UAE and Oman, as well as Iraqi mental health professionals.

The security situation has improved in Iraq and the meeting passed without incident. The feedback from delegates was very positive and it is hoped the meeting will herald the beginning of a new era of collaboration and development in the region.

\section{The mental health needs of the UK's Chinese children}

Sir: In 2005, the Department of Health for England set a five-year action plan, Delivering Race Equality in Mental Health Care. The aim was to encourage the development of services that were more appropriate and responsive to the needs of both adults and children in Black and minority ethnic communities.

The Chinese community is the third largest immigrant group in the UK. Despite this there are few existing data concerning the mental health of Britain's Chinese population and a recent systematic review concluded that there was insufficient evidence to make any meaningful comment on the prevalence of common mental health disorders in Chinese children and adolescents in the UK (Goodman et al, 2008).

Why do we know so little about this significant population of children? First, it is difficult to collect information from the Chinese community. In contrast to other ethnic minority groups, which often coalesce in urban areas, resulting in a high population density, the dispersed nature of the Chinese population makes data-gathering difficult (Cowan, 2001). Moreover, many data were collected via Chinese community organisations and may have therefore been subject to many different forms of bias (e.g. some people who identify themselves as Chinese may never attend community activities).

Paradoxically, although Chinese children are educationally among the highest achievers in the UK, many of their parents have limited literary skills and some of them are working unsociable hours in the catering business, which further limits their opportunities to develop their English language skills. This language barrier could impair the ability

Correspondence is welcome either on articles published in International Psychiatry or on aspects of current policy and practice in psychiatry in different countries. Letters (of up to 500 words) should be sent to:

Amit Malik MRCPsych, Consultant Psychiatrist, Hampshire Partnership NHS Trust, UK, email ip@rcpsych.ac.uk. 
of Chinese children to receive input from health professionals. For example, some Chinese parents may not feel confident in bringing a young person with a suspected mental health difficulty to see a general practitioner, and Chinese carers may find it difficult to understand concerns regarding their child's emotional well-being as communicated to them by professionals such as teachers. Furthermore, systemic (e.g. family therapy) or parenting-based work may be difficult, especially in the absence of an independent (non-family) interpreter.

In addition to language issues, cultural factors may also shape help-seeking behaviour. Although present across cultures, the problem of stigma remains prominent among the Chinese population. For example, a preliminary assessment of the mental health needs of Chinese young people in Birmingham revealed that the majority of them perceived mental illness as being 'crazy' and 'associated with violence' (Fung, 2005). Such cultural and individual attitudes could serve to prevent or at least delay young people and their families from engaging with mental health services.

Research is urgently needed in order to develop an understanding of the mental health needs of Chinese children in the UK. This should feed into developing programmes of public education and more culturally acceptable services in order to increase the Chinese community's access to timely help for young people. Without this, UK health services will find it difficult to meet agreed racial equality goals.

W. Cheng ${ }^{1}$ and P. A. Tiffin ${ }^{2}$

${ }^{1}$ Specialty Registrar in Child and Adolescent Psychiatry, Northumberland, Tyne and Wear NHS Trust, email wilson.cheng@ntw.nhs.uk; ${ }^{2}$ Clinical Senior Lecturer and Honorary Consultant in the Psychiatry of Adolescence, Durham University and Tees, Esk and Wear Valleys NHS Foundation Trust

Cowan, C. (2001) The mental health of Chinese people in Britain: an update on current literature. Journal of Mental Health, 10, 501-511.

Fung, R. (2005) Stigma of mental illness among Chinese people. Psychiatric Bulletin, 29, 193

Goodman, A., Patel, V. \& Leon, D. A. (2008) Child mental health differences amongst ethnic groups in Britain: a systematic review. BMC Public Health, 8, 258.

\section{Proportionality of legal discrimination}

SHe= The article by Zigmond (2009) made for SI interesting reading. Mental health law is about balancing the need to detain people in order to protect them or other people from harm and the need to respect people's human rights and autonomy. In the UK, there was much concern during the development of recent mental health legislation, in particular the Mental Capacity Act 2005, that the government had got this balance wrong. Many of these concerns have been addressed in the updated Code of Practice to the 1983 Mental Health Act, which is an essential guide to practising under the Act (Department of Health, 2008). There is no legal duty to comply with the Code, but professionals must have regard to it and record the reason for any departure from the guidance (which can be subject to legal challenge).
Safeguards regarding deprivation of liberty, which address the 'Bournewood gap' concerning the detention of compliant incapacitous individuals, in the Mental Capacity Act have been one of the highlights of the changes introduced (Hall \& Ali, 2009). The mental health legislation in England and Wales is based on risk. One of the arguments for having risk as the main focus is the fact that mental illness leads to loss of insight, which makes it impossible for the sufferer to make an informed decision. The proponents of the other view argue that having a different criterion for compulsory treatment (risk rather than capacity) for mental illness results in further discrimination against people who are mentally ill and can only help to enhance stigma.

The European Court of Human Rights has had some impact on the Mental Health Act 1983 and its interpretation; it has not, however, set a high standard for modern mental health services. Some judgements may strike present-day clinicians not so much as protecting patients' rights but as permitting undesirable practices. This is perhaps not surprising when it is considered that the European Convention on Human Rights, signed in 1950, harbours old prejudices against those with mental illness (Bindman et al, 2003). These are apparent in the language of Article 5, which groups persons of 'unsound mind' with 'vagrants' and 'drug addicts' as being exempted from the protections afforded to others. In incorporating the European Convention on Human Rights, the UK Human Rights Act 1998 perpetuates rather than challenges the lesser regard for the autonomy of patients with mental illness than of other medical patients, which is at the heart of conventional mental health legislation (Szmukler \& Holloway, 2000). If the courts do begin to scrutinise the proportionality of clinical decisions - a function currently carried out only haphazardly by mental health review tribunals (Perkins, 2000) - the impact could be considerable. Many of the cases involving the European Convention on Human Rights to date have concerned patients in maximum security settings or with significant forensic histories, and it is not surprising that compulsory treatment is often found to be justified or the infringement of rights to be proportionate. However, a decision, for example, to compel a 'revolving door' patient without a history of offending to accept community treatment might be judged to be disproportionate if founded on weak scientific evidence of risk or benefit.

Dr Partha Gangopadhyay Clinical Teaching Fellow and Honorary Specialty Registrar in Forensic Psychiatry, University of Aberdeen, UK, email p.gangopadhyay@abdn.ac.uk

Bindman, J., Maingay, S. \& Szmukler, G. (2003) The Human Rights Act and mental health legislation. British Journal of Psychiatry, 182, 91-94

Department of Health (2008) Code of Practice, Mental Health Act 1983. TSO (The Stationery Office).

Hall, I. \& Ali, A. (2009) Changes to the Mental Health and Mental Capacity Acts: implications for patients and professionals. Psychiatric Bulletin, 33, 226-230.

Perkins, E. (2000) Decision-making in mental health review tribunals. In Shaping the New Mental Health Act: Key Messages from the Department of Health Research Programme, pp. 29-32. Department of Health.

Szmukler, G. \& Holloway, F. (2000) Reform of the Mental Health Act: health or safety? British Journal of Psychiatry, 177, 196-200.

Zigmond, T. (2009) Mental illness and legal discrimination. International Psychiatry, 6, 79-80. 